\title{
A Prospective Study of Nasal Septal Deformities in Kashmiri Population Attending a Tertiary Care Hospital
}

\author{
Ayaz Rehman ${ }^{1}$, Sajad Hamid ${ }^{2}$, Mushtaq Ahmad ${ }^{3}$, Arsalan F. Rashid ${ }^{4}$ \\ ${ }^{1}$ Department of Otolaryngology, SKIMS Medical College, Srinagar, India \\ ${ }^{2}$ Department of Anatomy, SKIMS Medical College, Srinagar, India \\ ${ }^{3}$ Department of Otolaryngology, SKIMS Medical College, Srinagar, India \\ ${ }^{4}$ SKIMS Medical College, Srinagar, India \\ Email: drayazrehmanent@gmail.com,drsajadk@rediffmail.com, masangoo@gmail.com
}

Received August 6, 2012; revised September 14, 2012; accepted October 4, 2012

\begin{abstract}
The aim of this study is to determine the percentage of septal deformities in symptomatic patients in Kashmiri population, identified at otolaryngology clinic of a referral \& a teaching tertiary care hospital SKIMS Medical College, Bemina, Srinagar, where 429 patients with nasal septal deviation were identified. All of the patients underwent nasal examination by anterior rhinoscope and nasal endoscopy. Pathological septal deformities were identified \& grouped into five types by using SL classification. The frequency of nasal septal deformation has been found to be 151 (35.19\%) in males and 278 (64.80\%) in females .The age incidence showed that most of the patients between second and fifth decades. The distribution of the five types of septal deformity was $19 \%, 3.5 \%, 10.48 \%, 6.75 \%, 0.93 \%$ \& Combinations $60.10 \%$ (9.3\%, 20.97\%, 8.39\% and 21.44\%) respectively. The most common presentation in overall patients were nasal obstruction $80 \%$ and headache $50 \%$. Nasal septal deviation was more prevalent in females. Nasal obstruction was the most common presenting complaint in all over types of nasal septal deviation. So, early diagnosis and intervention can avoid the related complications and thus help normal life and learning.
\end{abstract}

Keywords: Nasal Septum; Deviation; SL Classification

\section{Introduction}

Septum nasi, which consists of cartilagenous and osseous tissues, separates the nasal cavity into two halves. The nasal septum also supports the external nasal osseocartilagenous structures that are located on it. It has been suggested that the nasal septum is usually a midline structure until the age of 7 and it deviates mostly to the right side thereafter [1]. While some authors consider the nasal septum as a figure representing the displacement of maxilla during growth and development, this suggestion has not been confirmed [2]. Deviation of the septum may take the form of a "C" or "S" or may look like a large spur [3]. Cottle classified the deviations of the septum into four different groups: subluxation, large spurs, caudal deflection and tension septum [4]. On the other hand, Guyuron's classification proposes 6 different forms: tilt, anteroposterior C, cephalocaudal C, anteroposterior S, cephalocaudal S and wide spurs [5].Gray reported a prevalence of bilateral nasal septal deviation in $27 \%$ and unilateral in 31\% from a series of 2380 infants [6]. Van der Veken showed that the prevalence of septal deviation in children increases from $16 \%$ to $72 \%$ in a linear fashion from 3 to 14 years of age [7]. Among a cohort of 2112 adults, Gray reported a septal deviation rate of 79\% [6]. In radiological studies lower prevalence rates of septal deviation are reported with Calhoun finding septal deviation in $19.5 \%$ and Jones in $24 \%$ of control populations [8,9]. Among children of 2 to 12 years CT evidence of sinus pathology is found in $60 \%$ of symptomatic and $46 \%$ of normal children [10]. Jensen reported sinus abnormality on plain radiology assessment in $27 \%$ of his patients about to undergo septoplasty [11]. In addition, Matschke reported sinus pathology in $50 \%$ of a series of 150 patients who had rhinomanometrically proven nasal septal deformity and obstruction [12]. Elahi, Calhoun and Yousem reported a higher incidence and severity of sinus disease with increasing septal deviation in the region of the ostiomeatal complex (OMC] as assessed by CT scan $[8,13,14,15]$. Danese found an association between septal ridges and spurs and ipsilateral sinus disease as assessed by CT scan [16]. Many septal deviations are due to direct trauma and this is frequently associated with damage to other part of the nose such as fracture of the nasal bone [17]. In many patients with septal deviation there is no obvious history of trauma but abnormal intrauterine posture may result in compression forces acting on the nose 
and upper jaw like in persistent occiptoposterior presentation. Displacement of septum can result and the nose can be exposed to further torsion forces during parturition. Dislocations are more commom in primipara \& when the second stage of labour lasted for more than 15 minutes). It was found that high-birth weight babies, delivered by vaginal route (55\%), to a primi mother are more likely to have DNS after birth. Moreover, intrauterine malposition particularly breech (45\%) and prolonged labour seemed to play a role in newborn DNS [18]. Dislocations are generally to the right in the case of left occipito-anterior presentation \& to the left with right occipito-anterior presentation. Subsequent growth of nose accentuates these asymmetries. Combined septal deformity involving all septal components caused by compression across the maxilla regarding to the birth molding theory, while the anterior cartilage deformity of the quadrilateral septal cartilage caused by direct trauma [19-24]. Grymer and Melsen (1989) who were able to examine 41 pairs of identical twins suggested that anterior lesions were due to an external cause- trauma where as the posterior lesions due to genetic factors [25]. A recent study by Ranko Mladina (2003) was found type 6 septal deformity (Mladina's classification) in 21 out of 22 both father and mothers of these children with type 6 septal deformity. The high correlation in the incidence of type 6 nasal deformities in mothers and their children and in fathers and their children suggests that that this type of nasal deformity is inherited [26]. Differential growth between nasal septum \& palate causes the nasal septum to buckle under pressure.

The normal nasal septum is straight, symmetrical and meets evenly arched palate in midline [19,20]. Varying degree of nasal septal deformity occur at a considerable rate at birth and in the adults with a suggestion that the nasal septal deformity of adults cases has commenced at birth, and increasing with growth and age [20-23]. Nasal septal deformity is one of the most common disorders in human beings. These deformities may cause and aggravate sinusitis, upper airway infection and various middle ear infections. Symptoms such as nasal obstruction and postnasal discharge are associated with nasal septal deformity. The stuffed nose has an adverse effect on the development of the child. Also, it has been reported that nasal septal deformity has an important effect on the facial growth and development, especially in the first decade of life [27-30]. Surgical correction may be needed in order to alleviate these conditions. Nasal septum deviations also bear importance with respect to endoscopic sinus surgery and septal plasty operations. Particularly, a deviated septum may hamper the accessibility to the region where the opening of the maxillary sinus is located during such interventions. Besides this, an increased incidence and severity of bilateral chronic sinus disease was present with increasing deviations of the septum. Deviations represent the most frequent pathological condition in the nasal septum and submucosal resection is the most frequently applied modality for the treatment of septal deviations. Detailed knowledge about the anatomy of the deviation guides the surgeon during operations and lack of it may result in treatment failure. Numerous epidemiological studies on the frequency of nasal septal deviation in human (from newborn period to adulthood] have been performed over the last decades. These studies were conducted on different age groups and used various classification .They showed rather variable prevalence rates, ranging from $0.93 \%$ in India to $55 \%$ in Greece [31,32].

\section{Material and Methods}

The study is a Prospective one \& was conducted between July 2011 and July 2012, (429) symptomatic cases of nasal septal deviation were identified at the otorhinolaryngology outpatient clinic of a referral \& a teaching hospital SKIMS Medical College, Bemina, Srinagar, \& all of these symptomatic cases were included in the study. The exclusion criteria included the following:

- Non-Kashmiri patients

- Patients with past history of surgery to the nose

- Cases of coryza, allergic rhinitis, sinusitis and nasal polyposis

In all patients the following parameters were registered; age, sex, symptoms, allergic rhinitis, nasal polyposis, and past history of nasal surgery/history of trauma and type of nasal deformities. Firstly, each suspected patient answered a questionnaire about the presence or not of nasal obstruction, itching, aqueous rhinorrhea and sneezing. Then Nasal examination was performed on each patients first by using Killian nasal speculum without previous administration of vasoconstrictive agents then after topical application of $1: 1$ solution of $10 \%$ xylocaine to the nostrils for 10 minutes, an evaluation was made to verify the presence or not of nasal septum deviation, hypertrophy of nasal conchas, hyperemia, paleness, cyanosis of nasal mucosa or nasal concha degeneration, which would lead to the rhinitis clinical diagnosis, excluding the infectious ones. The nasal endoscopy was also done \& Pathological septal deformities were recorded according to the SL classification into five types depending upon the area of deformity as

\subsection{SL Classification Is Used to Record Pathologic Conditions of the Nasal Septum \& the Lateral Nasal Wall (Table 1)}

Coronal \& axial CT of the nose \& paranasal sinuses was also done to confirm the type of deviation \& to exclude all other pathological or non-pathological conditions 
(like allergic rhinitis) producing similar features. The septoplasty on treatment part was preffered alone or in combination with Rhinoplasty. Pre-operative \& Postoperative photographs were analysed in those patients who underwent septorhinoplasty. All the patients signed inferred consent for surgery. Patients with External nasal deformity along with deviated nasal septum underwent External Septorhinoplasty (92 cases). An inveted "Vshaped" midcolumellar incision was combined with bilateral marginal incision. The soft tissue envelope was elevated from the lower \& upper lateral cartilage .The medial crus were dissected free of the caudal septum. Bilateral mucoperichondrial \& mucoperiosteal flaps were raised posteriorly along cartilaginous \& bony septum. Inferiorly, the nasal spine was widely exposed. Once the entire bony \& cartilaginous septum was visualized, septoplasty was performed. Different osteotomies were peformed in these patients where nasal bone asymmetry was found. The columellar \& marginal incisions were closed, nasal packing was placed \& external nasal splints were applied. Patients were discharged home 1 - 3 days after surgery .The patients reported on 5th day after surgery \& thereafter twice a month for first 3 months \& then once three monthly for a total of one $\&$ a half years.

\section{Results (See Tables 2-7 and Figures 1-5)}

\subsection{Associated Deformity Were Also Seen in 186 Cases}

Deformity of nasal septum may be classified as

1) SPURS

SPURS are sharp angulations seen in the nasal septum occurring at the junction of vomer below with the septal cartilarge and/or ethmoid bone above. This type is due to vertical compression forces. Fractures that occur through nasal septum during injury to the nose may also produce sharp angulations. These fractures heal by fibrosis that extend to the adjacent mucoperichondrium. This increases the difficulty of flap elevation in this area.

\section{2) DEVIATIONS}

DEVIATIONS may be C-Shaped or S-Shaped. These can occur in either vertical or horizontal plane. It may also involve both cartilage \& bone. They may affect any of the three vertical components of nose causing a) Cartilagenous deviation: here upper bony septum \& bony pyramid are central but there is a dislocation/deviation of the cartilaginous septum \& vault; b) The "C" deviation: here there is a displacement of upper bony septum \& the pyramid to one side \& the whole of the cartilaginous septum \& vault to the opposite side; c) The "S" deviation: here the deviation of the middle-third (the upper cartilagenous vault \& associated septum) is opposite to that of the upper \& lower thirds.

3) DISLOCATIONS
In this the lower border of septal cartilage is displaced from its medial position \& projects into one of the nostrils

\section{Discussion}

The nasal septum plays an important role in both the appearance and function of the nose.

The Nasal septal deviation is quite common, but not necessarily symptomatic and its correction requires a focused, anatomically based treatment. Their incidence is higher in the leptorrhine noses found in Caucasians rather than Africans or Asians [17,33]. This study aimed at studying the types of nasal septal deviations present in kashmiri population and their aetiology and relation to nasal obstruction. As such nasorhinomanometric measurements were not employed. Approximately 80\% of humans have some kind of nasal septal deformity [34]. It is believed that a straight septum is the exception rather than the rule [33]. Septal deviations are extremely common, but are not usually severe enough to affect nasal function. In assessing the septum, the degree of deviation as well as the site of the deviation is important; Cottle (1960) has named five areas of septum regarding the site of deviation. Mladina in 1987 suggested classification of septal deformities into seven types. But, in our study we divide the septum into five areas as per SL Classification (Table 1). Assessment of septal deviations is usually quite obvious on anterior rhinoscopy, except in some cases with posterior deviation which need nasal endoscopy. Different rates of the prevalence of nasal septal deformities in different age groups have been reported. By far, several epidemiologic studies on nasal septal deviation have been conducted, in which different classification systems have been used [31,35-39]. On reviewing the studies in which Mladina's classification was used, type 1 and 2 deformities seem to constitute most of septal deformities. Subric and Mladina's study, using the same classification system demonstrate that the prevalence of deviations of the anterior (cartilaginous] and posterior (osseous) parts of the septum was $83.7 \%$ and $15.7 \%$ respectively [40]. Similar studies were conducted by Min et al. in Korea, but they included only the 6 - 9 age groups [40]. Ilhami Yildirm (2003) in Turkey found that anterior deformities were the most commonly encountered types in the pre-school children, but the occurrences of posterior deformities was relatively increased as the age increased. In their study, neither the distribution of nasal septal deformities types nor the overall prevalence showed any statistically significant difference between both sexes [41]. A recent study conducted by Rao J. in India demonstrated that horizontal deviations (63\%) followed by vertical deviations. The male: female ratio in their study was 69:31 and the age incidence between second to fourth decades. In their study, presenting 
Table 1. SL classification is used to record pathologic conditions of the nasal septum \& the lateral nasal wall.

\begin{tabular}{|c|c|}
\hline S & Septum Nasi \\
\hline 0 & No evidence of Septal deformation \\
\hline 1 & Septal deviation confined to Vestibulum nasi \\
\hline 2 & Septal deviation confined to the nasal valve area \\
\hline 3 & Septal deviation confined to the Attic \\
\hline 4 & Septal deviation Confined to the Anterior turbinate area \\
\hline 5 & Septal deviation confined to the Posterior turbinate area \\
\hline $\mathrm{X}$ & $\begin{array}{c}\text { The minimum requirements to assess the Septal deviation } \\
\text { cannot be met }\end{array}$ \\
\hline $\mathbf{L}$ & Lateral Nasal Wall \\
\hline $\mathrm{n}$ & No evidence of pathology confined to lateral nasal wall \\
\hline $\mathrm{P}(\mathrm{s})$ & Polyp(polyposis nasi) \\
\hline c & Concha bullosa \\
\hline $\mathrm{h}$ & Inferior turbinate hypertophy \\
\hline $\mathrm{t}$ & Tumour \\
\hline $\mathrm{r}$ & Rhinitis \\
\hline $\mathrm{X}$ & $\begin{array}{c}\text { The minimum requirements to assess the septal deviation } \\
\text { cannot be met }\end{array}$ \\
\hline $\mathbf{O}$ & Other \\
\hline $\mathrm{L}$ & Left nasal passage \\
\hline $\mathrm{R}$ & Right nasal passage \\
\hline
\end{tabular}

Area 1: Septal deviation confined to vestibulum nasi; Area 2: Septal deviation confined to nasal valve area; Area 3: Septal deviation confined to Attic; Area 4: Septal deviation confined to Anterior turbinate area; Area 5: Septal deviation confined to Posterior turbinate area.

complaints showed that 74 of 100 patients had nasal obstruction and 41 had nasal discharge. Headache was the complaint in 20 and sneezing in 15, the other problems seen in small number of patients were throat discomfort, postnasal drip, epistaxis and snoring [18]. Deviated or crooked septal cartilage is usually due to two causes; congenital disproportion with the cartilage being too long to its location or due to trauma sustained earlier in life [42]. The nose is the most commonly injured facial structure [43]. This should produce a higher incidence of past history of trauma. However, in many people with DNS there is no obvious history of trauma [44]. It is also difficult for people to remember injuries or small accidents that occurred early in life or in their childhood. $65 \%$ patients in our series gave a history of trauma. According to Hinderer [45], there are three growth periods in the early development of the nose: the first five years of rapid growth; the next five years of relative quiescence; and the last five years of rapid growth. Hence, injuries in periods of rapid growth will result in lasting deformities. The cause according to some can be explained by birth molding theory of Gray $[20,21]$. The incidence of nasal deformities in newborn infants varies from $1.45 \%$ to $6.3 \%[22,46]$ The cadual border of the septal cartilage extends beyond the nasal spine and thus can be subjected to forces that will lead to either dislocation from its attachment to the nasal spine or fracture of the cartilage vertically [42].

In our study, the total number of DNS cases were 429 \& male:female ratio was 35:65 (Table 2, Figure 1). The presenting complaints showed that the nasal obstruction were the most frequent $80 \%$,followed by headache $50 \%$, post nasal drip 30\% and throat discomfort 25\% (Figure 2). In our study, the prevalence of deviation in the Areas $\mathrm{I}-\mathrm{V}$ is $19 \%, 3.5 \%, 10.48 \%, 6.75 \%$ \& $0.93 \%$ respectively. The deviation is also seen in combinations as Areas (I \& II), (II \& III), (II \& IV) \& (II, III, IV) is $9.3 \%$, 20.04\%, $8.39 \%$ \& $21.44 \%$ respectively. The most frequent deviations are seen in Area I (19\%), followed by type Area III (10.48\%), Area IV (6.75\%) \& Area II (3.5\%) where as Area $\mathrm{V}$ deviations were the least frequent and represent $0.93 \%$. In Combination types, the most frequent type deviation were seen in Areas (II, III, IV): $21.44 \%$, followed by $20.04 \%$ in Area (II, III) \& the least frequent were seen in Areas (I, II): 9.3\% (Table 3). In our study, traumatic etiology predominates (Figure 3) \& right sided-deviation is towards higher side compared to leftsided. (Figure 4) The Adult: Child ratio in our study was 68:32 (Figure 5). The results of earlier studies on the prevalence of types of septal deformities point to that deformities of the anterior (cartilaginous) parts of the septum were the only ones observed in the youngest age group (2 - 6 years), where as older age groups were associated with a gradually increasing prevalence of deformities involving posterior (bony) parts of the septum which is consistent with our results. The nasal septal deviation occurs at a higher frequency in older children and in adults which suggest that a noncongenital etiology is responsible for nasal septal deviation. Maran [47] said that age and race as a risk factors for nasal trauma should be kept in mind. Takahashi [48] reported a study showing the racial distribution of nasal septal deformities. In, our study, the other features seen were; External nasal deformity were also seen in 92 cases (Table 4), different patterns of deviations in nasal septum seen in 94 cases (Table 5), With hypertrophy of turbinates seen in 408 cases (Table 6) \& Associated CT-Scan findings seen in 156 cases as variants like Concha bullosa, Paradoxical middle turbinate \& Pneumatic septum (Table 7).

Table 2. Total No. of deviated nasal septum (DNS) cases: 429.

\begin{tabular}{ccc}
\hline $\begin{array}{c}\text { Deviated Nasal } \\
\text { Septum (DNS) }\end{array}$ & Right Side & Left Side \\
\hline Total No. of Cases & $255(59.44 \%)$ & $174(40.55 \%)$ \\
\hline
\end{tabular}




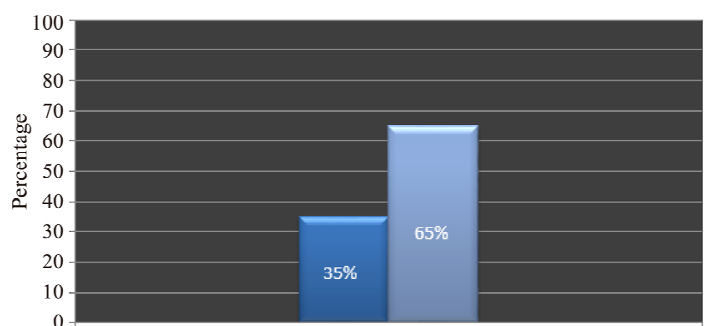

Figure 1. Percentage of male $\&$ female DNS cases.

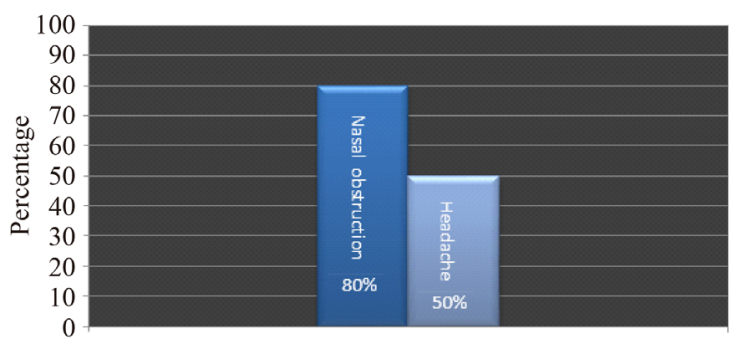

Figure 2. Main clinical presentations of DNS cases.

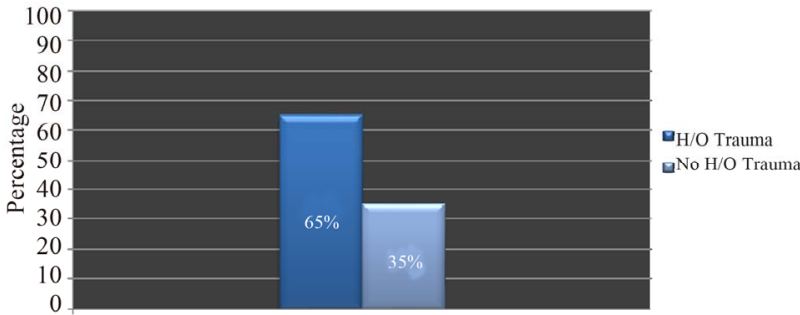

Figure 3. Percentage of cases with respect to etiology of DNS.

Table 3. Area-wise distribution of DNS cases.

\begin{tabular}{|c|c|c|}
\hline Deviated area & Total No. of cases & Right/left distribution \\
\hline Area I & $82(19 \%)$ & $\begin{array}{l}\text { Right: } 46 \text { (56\%), } \\
\text { Left: } 36 \text { (44\%) }\end{array}$ \\
\hline Area II & 15 (3.5\%) & $\begin{array}{l}\text { Right: } 10 \text { (66.36\%), } \\
\text { Left: } 5 \text { (33.33\%) }\end{array}$ \\
\hline Area III & 45 (10.48\%) & $\begin{array}{c}\text { Right: } 33 \text { (73.3\%), } \\
\text { Left: } 12 \text { (26.7\%) }\end{array}$ \\
\hline Area IV & 29 (6.75\%) & $\begin{array}{c}\text { Right: } 21 \text { (72.4\%), } \\
\text { Left: } 8 \text { (27.6\%) }\end{array}$ \\
\hline Area V & $4(0.93 \%)$ & $\begin{array}{c}\text { Right: } 3 \text { (75\%), } \\
\text { Left: } 1 \text { (25\%) }\end{array}$ \\
\hline Areas (I + II) & 40 (9.3\%) & $\begin{array}{l}\text { Right: } 20 \text { (50\%), } \\
\text { Left: } 20 \text { (50\%) }\end{array}$ \\
\hline Areas (II + III) & $86(20.04 \%)$ & $\begin{array}{l}\text { Right: } 56 \text { (65.11\%), } \\
\text { Left: } 30 \text { (34.88\%) }\end{array}$ \\
\hline Areas (II + IV) & 36 (8.39\%) & $\begin{array}{l}\text { Right: } 16 \text { (44.44\%), } \\
\text { Left: } 20 \text { (55.66\%) }\end{array}$ \\
\hline Areas (II + III + IV) & 92 (21.44\%) & $\begin{array}{l}\text { Right: } 50 \text { (54.34\%), } \\
\text { Left: } 42(45.66 \%)\end{array}$ \\
\hline
\end{tabular}

Area I: septal deviation confined to vestibular nasae; Area II: septal deviation confined to nasal valvular area; Area III: septal deviation confined to attic; Area IV: septal deviation confined to anterio turbinate area; Area V: septal deviation confined to posterior turbinate area.

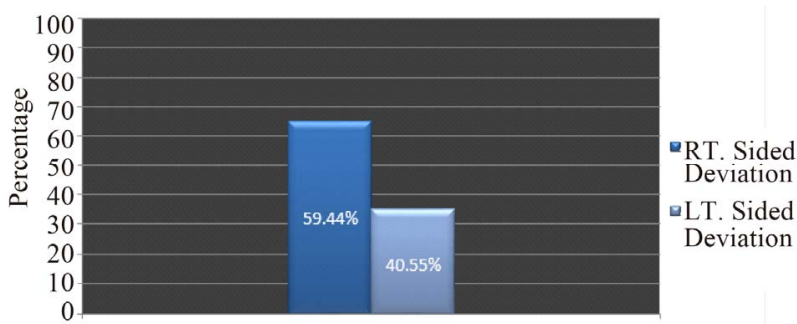

Figure 4. Percentages of cases with right/left sided deviation.

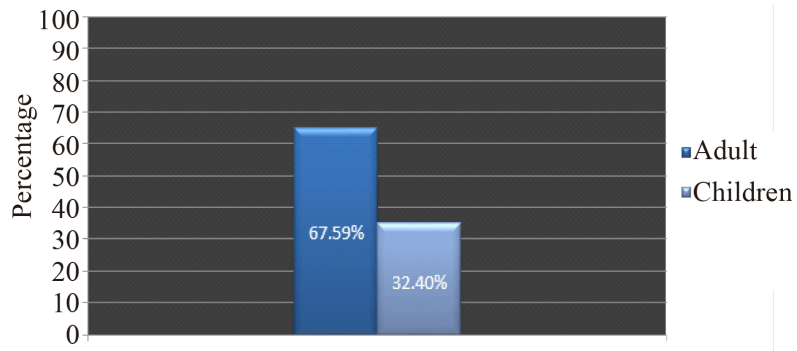

Figure 5. Percentage of adult \& children (as DNS cases).

Table 4. Shows cases associated with external deformity of nose.

\begin{tabular}{cccc}
\hline External Deformity & Depressed & Hump & Axis Depressed \\
\hline Total No. of Cases & 56 & 32 & 4 \\
\hline
\end{tabular}

Table 5. Shows cases various types of deviations in nasal septum.

\begin{tabular}{lcc}
\hline Internal Deformity & C-Shaped & S-Shaped \\
\hline Total No. of Cases & 52 & 42 \\
\hline
\end{tabular}

Table 6. Other associated nasal features: hpertrophy of turbinates seen in 408 cases as.

\begin{tabular}{ccc}
\hline Hypertrophy & Total No. of Cases & Distribution \\
\hline Inferior Turbinate & 197 & Right: 111, Left: 86 \\
$\begin{array}{c}\text { Middle Turbinate } \\
\text { (Inferior +Middle) } \\
\text { Turbinates }\end{array}$ & 41 & Right: 32, Left: 9 \\
\hline
\end{tabular}

Table 7. Additional CT-scan findings were seen in 156 cases as variants.

\begin{tabular}{ccc}
\hline CT-Finding & Total No. of Cases & Right/Left Distribution \\
\hline $\begin{array}{c}\text { Concha Bullosa } \\
\text { Paradoxical Middle } \\
\text { Turbinate }\end{array}$ & 102 & Right: 62, Left: 40 \\
Pneumatic Septum & 33 & - \\
\hline
\end{tabular}

However, given that the growth of the septum continues throughout childhood, our results do not preclude the possibility of a genetic predisposition to the later devel- 
opment of a deviated nasal septum [49]. Differences in the results retrieved from the afore-mentioned studies may be related to the age groups studied. On the other hand, in the study conducted by Kawalsky and Przemyslaw [24] nasal septal deformity was found to be $22.2 \%$ in children born by spontaneous delivery but only $3.9 \%$ among the infant delivered by caesarean section. In the light of this information, it can be thought that the different results found may be related to different age groups, traumatic factors including birth injury as well as racial factors.

\section{Clinical Significance}

We found that the prevalence of Nasal septal deviations and the occurrence of the posterior deformities was relatively increased as the age increased. Also the percentage of the nasal septum deformities change with age. Deviation of the nasal septum was more prevalent in females. The risk of occurrence of the nasal septum deformities increases after nasal injury. Surgical correction may be needed in order to alleviate these conditions. Nasal septum deviations also bear importance with respect to endoscopic sinus surgery and septoplasty operations. Particularly, a deviated septum may hamper the accessibility to the region where the opening of the maxillary sinus is located during such interventions. Besides this, an increased incidence and severity of bilateral chronic sinus disease was present with increasing deviations of the septum. Deviations represent the most frequent pathological condition in the nasal septum and submucosal resection is the most frequently applied modality for the treatment of septal deviations. Detailed knowledge about the anatomy of the deviation guides the surgeon during operations and lack of it may result in treatment failure. The anatomical variations which are most commonly associated with sinus pathology are septal deviations, true conchae bullosae and supplementary maxillary ostia but the latter one only when recycling is present. The knowledge of anatomical variations is most important in the surgical management and specifically in the prevention of complications the computed tomographic scans obtained in patients referred for evaluation for functional endoscopic sinus surgery were examined to determine the prevalence and significance of anatomic variants. Among the various anatomic variants, variations of the septum and middle turbinates, with or without anterior ethmoid sinus extensions, that could produce significant obstruction of the drainage pathways. However, where such obstructive patterns existed, an equal prevalence of patients with and without sinus disease was found in the presence of the same variant combination. Interpretation of the CT scan must reflect this focus on anatomy and function. The normal frontal recess, ostiomeatal unit, and sphenoethmoid recess are considered along with the anatomic variations that distort their appearance and predispose the patient to developing sinus disease. Recent and ongoing advances made in endoscopic surgical techniques require the radiologist to understand the anatomy and pathophysiology of the paranasal sinuses and nasal passage. Endoscopy and CT are complementary procedures, and, as such, the normal anatomic relationships and their CT appearances need to be well understood in order for radiologists to offer continued support as consultants to their clinical colleagues. Also, it has been seen that the septal deviation significantly diminishes drug delivery on the obstructed side, while using intranasal drugs [50].

\section{1)CT-SCAN(AXIAL VIEW)}
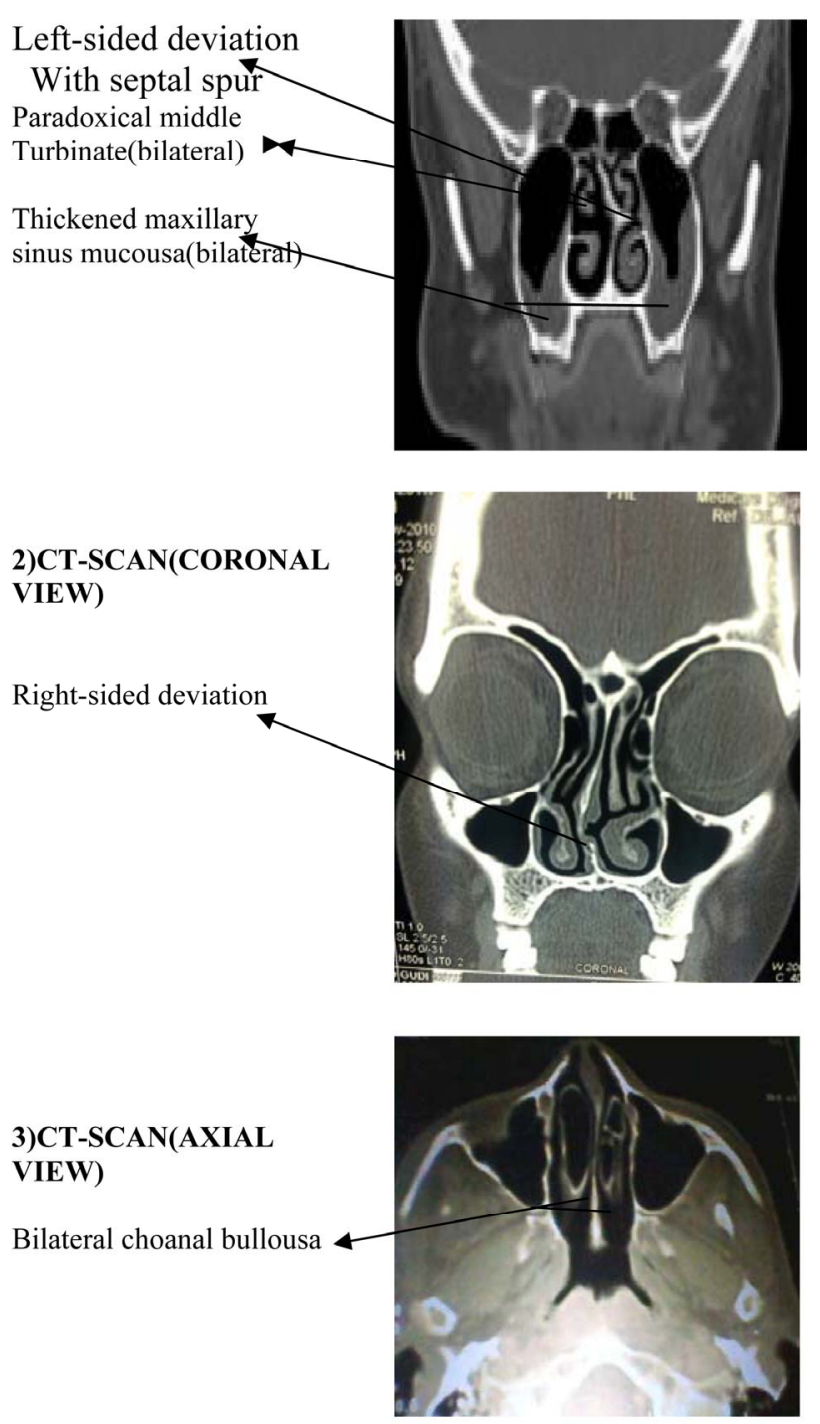

\section{REFERENCES}

[1] K. L. Moore, “Clinicaly Oriented Anatomy,” Williams \& Wilkins, Baltimore, 1994, p. 754. 
[2] D. H. Enlow, "Handbook of Facial Growth," 2nd Edition, W.B. Saunders Company, Philedelphia, 1992.

[3] P. J. Donald, “Anatomy and Histology, the Sinuses," Raven Press, New York, 1994.

[4] M. H. Cottle, "The Maxilla-Premaxilla Aproach to Extensive Nasal Septal Surgery,” Archives of Otolaryngology—Head \& Neck Surgery, Vol. 68, No. 3, 1958, pp. 301-313. doi:10.1001/archotol.1958.00730020311003

[5] B. Guyuron, C. D. Uzzo and H. Scull, "A Practical Classification of Septonasal Deviation and an Effective Guide to Septal Surgery,” Plastics \& Reconstructive Surgery, Vol. 104, No. 7, 1999, pp. 2202-2209.

doi:10.1097/00006534-199912000-00039

[6] H. Gary, “Gray’s Anatomy,” 40th Edition, Longman, 1973, p.1088, 1095.

[7] P. Van Der Veken, P. Clement, T. Buisseret, B. Desprechins, L. Kaufman and M. P. Derde, "CAT Scan Study of the Prevalence of Sinus Disorders and Anatomical Variations in 196 Children,” Rhinology, Vol. 28, 1990, pp. 177-184.

[8] K. H. Calhoun, G. A. Waggenspack, C. B. Simpson, J. A. Hokanson and B. J. Bailey, "CT Evaluation of the Paranasal Sinuses in Symptomatic and Asymptomatic Populations," Otolaryngology_Head and Neck Surgery, Vol. 104, No. 4, 1991, pp. 480-483.

[9] N. S. Jones, A. Strobl and I. Holland, "A Study of the CT Finding in 100 Patients with Rhinosinusitis and 100 Controls," Clinical Otoloaryngology \& Allied Sciences, Vol. 22, No. 1, 1997, pp. 47-51. doi:10.1046/j.1365-2273.1997.00862.x

[10] C. S. Cotter, S. Stringer, K. R. Rust and A. Mancuso, "The Role of Computed Tomography Scans in Evaluating Sinus Disease in Pediatric Patients,” International Journal of Pediatric Otorhinolaryngology, Vol. 50, No. 1, 1999, pp. 63-68. doi:10.1016/S0165-5876(99)00204-9

[11] J. Jensen and H. Dommerby, "Routine Radiological Examination of the Sinus before Septoplasty," Journal of Laryngology \& Otology, Vol. 100, No. 8, 1986, pp. 893896. doi:10.1017/S0022215100100283

[12] R. Matschke and A. Fliebach, "Septum Deviation and Concomitant Sinusitis,” HNO, Vol. 33, No. 12, 1985, pp. 541-544.

[13] M. M. Elahi, S. Frenkiel and N. Fageeh, "Paraseptal Structural Changes and Chronic Sinus Disease in Relation to the Deviated Septum,” Journal of Otolaryngology, Vol. 26, 1997, pp. 236-240.

[14] D. M. Yousem, D. W. Kennedy and S. Rosenberg, "Ostiomeatal Complex Risk Factors for Sinusitis: CT Evaluation,” Journal of Otolaryngology, Vol. 20, 1991, pp. 419424.

[15] M. M. Elahi and S. Frenkiel, "Septal Deviation and Chronic Sinus Disease,” American Journal of Rhinology, Vol. 14, No. 3, 2000, pp. 175-179. doi:10.2500/105065800782102735

[16] M. Danese, B. Duvoisin, A. Agrifolio, J. Cherpillod and M. Krayenbulh, "Influence of Naso-Sinusal Anatomic Variants on Recurrent, Persistent or Chronic Sinusitis. X-Ray Computed Tomographic Evaluation in 112 Pa- tients,” Journal of Radiologie, Vol. 78, No. 9, 1997, pp. 651-657.

[17] D. Brain, “The Nasal Septum, Scott-Brown’s Otolaryngology, Vol. 4,” Rhinology, 6th Edition, 1997.

[18] A. G. D. Maran, “The Fractured Nose,” In: A. G. Kerr and J. Groves, Eds., Scoot-Brown's Otolaryngology, Vol. 4. Butterworths, London, 1987, pp. 212-221.

[19] L. P. Gray, "Early Treatment of Septal Deformity and Associated Abnormalities," Modern Trend in Diseases of the Ear, Nose and Throat, 1972, pp. 219-236.

[20] L. P. Gray, "Deviated Nasal Sptum. Incidence and Eatiology," Annals of Otology, Rhinoogy and. Laryngology, Vol. 87, Suppl. 50, 1978, pp. 3-20.

[21] D. Brain, “The Etiology of Neonatal Septal Deviation,” Facial Plastic Surgery, Vol. 8, No. 4, 1992, pp. 191-193. doi:10.1055/s-2008-1064650

[22] S. E. Kent, A. P. Reid, E. R. Nairnand and D. J. Brain, "Neonatal Septal Deviations," Journal of the Royal Society of Medicine, Vol. 81, No. 3, 1988, pp. 123-135.

[23] H. Kawalski and P. Spiewak, "How Septum Deformations in Newborn Occur," International Journal of Pediatric Otorhinolaryngology, Vol. 44, No. 1, 1998, pp. 132135.

[24] L. F. Grymer and B. Melsen, "The Morphology of Nasal Septum in Identical Twins,” Lary, Vol. 99, 1998, pp. 642646.

[25] R. Mladina and M. Subaric, "Are Some Septal Deformities Inherited?” International Journal of Pediatric Otorhinolaryngology, Vol. 67, No. 12, 2003, pp. 12911294. doi:10.1016/j.ijporl.2003.07.007

[26] L. F. Grymer and C. Bosch, "The Nasal Setum and Development of the Midface. A Longitudinal Study of a Pair of Monozygotic Twins,” Rhinology, Vol. 35, No. 1, 1997, pp. 6-10.

[27] R. Mladin, "The Role of Maxillary Morphology in the Development of Pathological Septal Deformities," Rhinology, Vol. 25, No. 3, 1987, pp. 199-205.

[28] W. Pirsig, “Open Question in Nasal Surgery in Children,” Rhinology, Vol. 24, No. 1, 1986, pp. 37-40.

[29] L. Podoshin, R. Gertner, M. Fradis and A. Berger, "Incidince and Treatment of Deviation of Septum Innewborns,” Ear Nose \& Throat Journal, Vol. 70, No. 8, 1991, pp. 485-487.

[30] Y. M. Kim, et al., "Correlation of Asymmetric Facial Growth with Deviated Nasal Septum," Laryngoscope, Vol. 121, No. 6, 2011, pp. 1144-1148. doi:10.1002/lary.21785

[31] A. Korantzis, E. Cardamakis, E. Chelidonis and T. Papamihalis, "Nasal Septum Deformity the Newborn Infant during Labour," European Journal of Obstetrics \& Gynecology and Reproductive Biology, Vol. 44, No. 1, 1992, pp. 41-46. doi:10.1016/0028-2243(92)90311-L

[32] M. Subaric and R. Mladina, "Nasl Septum Deformities in Children and Adolescent: A Cross Sectional Study of children from Zagrep, Croatia,” International Journal of Pediatric Otorhinlaryngology, Vol. 63, No. 1, 2003, pp. 41-48. doi:10.1016/S0165-5876(01)00646-2 
[33] A. G. D. Maran and V. J. Lund, "Infectious and NonNeoplastic Disease,” Clinical Rhinology, Theime, Nasal Septal Deviation in Saudi Patients: Hospital Based Study, 45 Stuttgart, 1990, pp. 59-109.

[34] M. McKenzie, "Manual of Diseases of the Nose and the Throat," Churchill, London, 1880, p. 432.

[35] G. Strambis, "Incidence of Nasal Deformities in Young Populations," Prooceeding of the $x v$ Congress of the European Rhinology Society, Amsterdam, 1988, p. 60.

[36] J. J. Haapaniemi, J. T. Suonnpaa, A. J. Sa Imivalii and J. Tuominen, "Prevalence of Septal Deviations in SchoolAged Children,” Rhinology, Vol. 33, 1995, pp. 1-3.

[37] R. M. Neves-Pinto and M. S. Saraiva, “On the Incidence of Septal Deformities According to Mladina's Classification and Some Correlated Aspects,” Folha Med, Vol. 106, No. 3, 1993, pp. 73-76.

[38] Z. Jurkiewicz and B. O. Sosinska, "The Nasal Septum Deformities in Children \& Adolescent from Warsaw, Poland," International Journal of Pediatric Otorhinolaryngology, Vol. 70, No. 4, 2006, pp. 731-736.

[39] Y. G. Min, H. W. Jung and C. S. Kim, "Prevalance Study of Nasal Septum Deformities in Korea: Results of Nation-Wide Survey,” Rhinology, Vol. 33, No. 2, 1995, pp. 61-65.

[40] I. Yildirim and E. Okur, "The Prevalence of Nasal Septal Deviation in Children from Kahramanmaras, Turky," International Journal of Pediatricotolaryngology, Vol. 67, No. 11, 2003, pp. 1203-1206.

[41] J. J. Rao, E. C. V. Kumar, et al., "Classification of Nasal Septal Deviations-Relation to Sinonasal Pathology," India Journal of Otolaryngology and Head and Neck Surgery, Vol. 57, No. 3, 2005, pp. 199-201.

[42] R. B. Sessions and T. Toost, "The Nasal Septum,” In: C.
W. Cummings, J. M. Fredrickson, L. A. Harker, et al., Eds., Otolaryngology-Head and Neck Surgery, Vol. I, Mosby Year Book, St. Louis, 1993, pp. 786-793.

[43] G. W. Facer, "A Blow to the Nose; Common Injury Requiring Skillful Management,” Postgraduate Medicine, Vol. 70, No. 1, 1981, pp. 83-87,90,92.

[44] D. Brain, "Anatomy, Physiology, and Ultrastructure of the Nose,” In: I. Macky, Ed., Rhinitis-Mechanism and Management, Royal Society of Medicine Services Ltd., London, 1989, pp. 11-31.

[45] K. H. Hinderer, "Fundamentals of Anatomy and Surgery of the Nose,” Aesculapius Publishing Co., Birmingham, 1971.

[46] M. Sorri, K. Laitakari, J. Vainio-Mattila and A. L. Hartikainen-Sorri, "Immediate Correction of Congential Nasal Deformities: Follow-Up of 8 Years,” International Journal of Pediatric Otorhinolarynology, Vol. 19, No. 3, 1990, pp. 277-283. doi:10.1016/0165-5876(90)90008-F

[47] R. Takahashi, "The Condition of Nasal Septum and the Formation of Septal Deformity,” Rhinology, Vol. 5, No. 1, 1988, pp. 23-27.

[48] S. D. Reitzen, W. Chung and A. R. Shah, "Nasal Septal Deviation in the Pediatric \& Adult Populations," Ear Nose and Throat Journal, Vol. 90, No. 3, 2011, pp. 112 115.

[49] A. Bhattacharjee, S. Uddin and P. purkaystha, "Deviated Nasal Septum in the newborn-A 1-Year Study,” Indian Journal of Otolaryngology and Head \& Neck Surgery, Vol. 57, No. 4, 2005, pp. 304-308.

[50] D. O. Frank, et al., "Deviated Nasal Septum Hinders Intranasal Sprays: A Computer Simulation Study,” Rhinology, Vol. 50, No. 3, 2012, pp. 311-318. 